\title{
Research and Exploration on Cultivation Mode of Practical Applied Vehicle Engineering Talents \\ Honggang Yang ${ }^{1, a,{ }^{*}, \text { Weiguang Yuan }}{ }^{1, b}$ \\ ${ }^{1}$ Automotive institute of Shanghai DianJi universtiy, Shanghai, China \\ ayanghg@sdju.edu.cn, byuanwg@sdju.edu.cn \\ Corresponding Author
}

\begin{abstract}
Combined with investigation on business needs and construction principle of practical applied talents, cultivation objectives of practical applied vehicle engineering talents are demonstrated. To explore cultivation mode of practical applied vehicle engineering talents, the training program is gradually improved, and curriculum is constructed, in order to provide reference for excellent connection of university cultivation and social demands.
\end{abstract}

Keywords: Vehicle engineering, Cultivation mode, Practical applied talents.

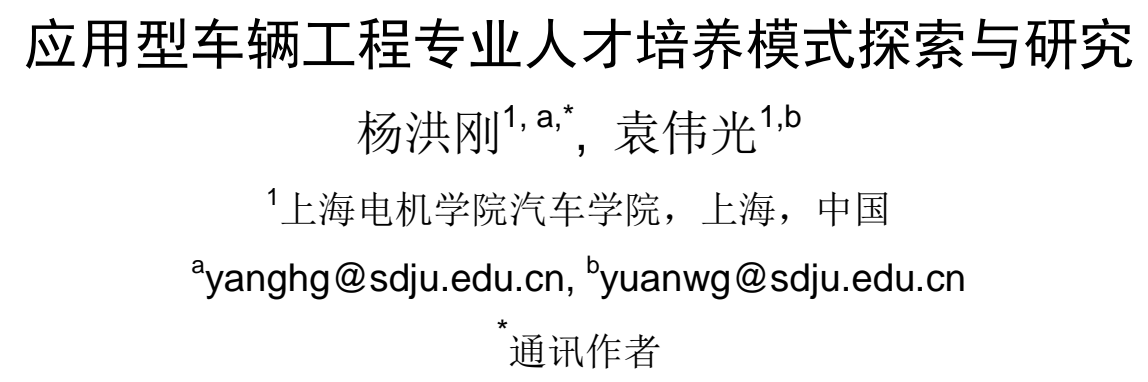

中文摘要.通过对企业需求的深入调研, 结 合应用型专业人才的建设原则, 明确了应用 型车辆工程专业人才的培养目标, 逐步完善 人才培养方案, 构建课程体系, 探索应用型 车辆工程专业人才培养模式, 为实现大学培 养与社会需求的良好对接提供参考。

关键词: 车辆工程; 人才培养模式; 应用型 人才;

\section{1. 引言}

车辆工程专业拥有广泛的知识体系网 络, 不仅涵盖了机械设计、动力机械工程、 牵引动力传动、金属材料等传统的基础理 论, 而且不断地扩展外延, 与计算机技术、 电子技术、交通运输、控制技术等专业也有 密切的联系。目前, 我国设有车辆工程专业 的高校数量已显著增加。各个高校的车辆工 程专业的发展途径和专长也各不相同, 培养 方案也各有侧重, 有的侧重于汽车底盘, 有 的侧重于汽车车身, 有的侧重于汽车电子控 制等等。 
上海电机学院汽车学院于2009年设立 了车辆工程专业。近年来, 学院积极探索车 辆工程专业人才的社会需求, 合理规划专业 发展定位, 制定培养目标。目前已与上海同 捷科技股份有限公司签署校企合作应用型 人才培养框架协议, 力争建立科学的人才培 养模式, 从而提高应用型车辆工程专业人才 的培养质量。

\section{2. 应用型车辆工程专业人才的培养目标与 规格}

“技术立校，应用为本” 是我校特色鲜 明的办学指导方针, 这要求我们必须以学生 为根本, 以知识为基础, 以能力为核心, 以 市场需求为导向, 培养具有创新精神, 且适 应社会经济发展需要的应用型工程技术人 才。因此, 在应用型人才培养模式的探索过 程中, 应注重产学结合, 充分发挥校企资源 优势, 实现课内与课外相结合, 教学与研究 相结合。一方面积极走访上海同捷科技股份 有限公司、上海申龙客车股份有限公司等汽 车企业, 针对汽车企业对车辆工程专业人才 的需求展开调研与分析, 深入学习汽车企业 的文化与理念, 借用企业人才资源、先进技 术提升学生的培养质量与教师的实力; 另一 方面为教师、学校与企业搭建深度融合与全 面了解的平台, 实现产学研水平的促进与提 升。

根据我校既有资源优势, 结合同捷公司 等企业对人才的需求状况和学生自身发展 的目标追求, 我校应用型车辆工程专业人才 的培养目标是: 技能

（1）具有基本理论、基本知识和基本

掌握汽车产品的计算机辅助设计技术、 现代汽车制造技术、汽车电子技术、汽车检 测与维修等车辆工程方面的基本理论、基本 知识和基本技能。

（2）获得卓越工程师的基本训练

具备良好的职业素养、较强的自学能力 和创新意识, 掌握车辆工程领域中设计、制 造、生产、试验等方面分析和解决问题的方 法和能力。

(3) 具备车辆工程领域的技术应用能 力
能够在汽车整车企业、零部件企业及其 相关企事业单位从事汽车零部件、汽车电器 与电子领域的设计、性能测试与技术服务等 方面的工作, 培养成为车辆工程专业应用型 高级工程技术人才。

\section{3. 应用型车辆工程专业人才培养模式的构 建}

完善的培养体系决定了人才的培养质 量, 是实现培养目标的基本保证。在汽车企 业对车辆工程专业的需求调研与分析的基 础上, 针对车辆工程专业的培养体系逐步进 行完善。重点针对课程设置和教学内容、方 式和方法, 合理而适度压缩理论教学课时比 例, 适当增加实践环节课时比例, 注重学生 潜力和特长的充分发挥, 提高动手和实际应 用能力。建立的应用型车辆工程专业人才培 养体系如图1所示, 主要分为理论教学模块、 实践技能培养模块和综合素质培养模块三 个部分。

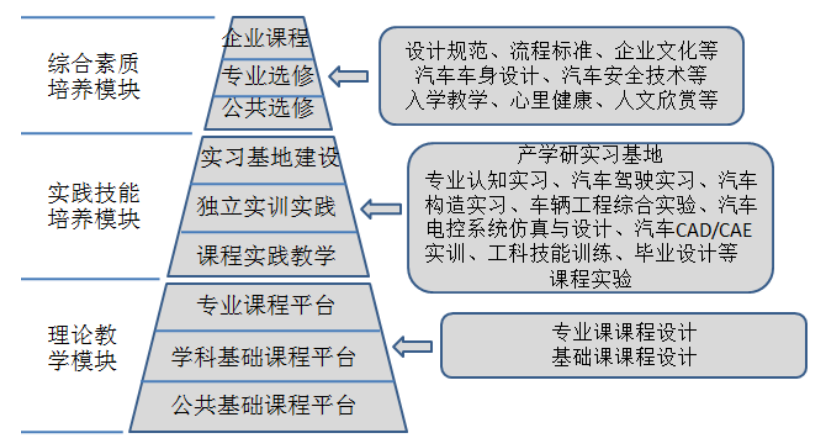

图1 应用型车辆工程专业人才培养体系图

\section{1 理论教学模块}

\section{1 .1 公共基础课程平台建构}

搭建以数学和工程力学为主的公共基 础课平台, 使学生建立牢固的工程科学基础 理论背景。学习课程主要包括高等数学、线 性代数、大学物理、大学计算机基础、高级 语言程序设计等。

\subsection{2 学科基础课程平台建构}

构建专业基础知识的理论学习平台, 使 学生具备宽泛的汽车工程专业背景, 课程主 要包括机械制图、理论力学、材料力学、汽 车构造、汽车理论、发动机原理、数模电子 技术等。

\section{1 .3 专业课程平台建构}


搭建以汽车设计、汽车电器与电子控制 技术、汽车电控系统仿真与设计、汽车实验 技术等为主的专业课程平台。使学生在基本 理论知识的基础上, 进一步有针对性的、深 入的掌握汽车零部件设计与分析、汽车电器 与电子领域的设计、性能测试与技术服务等 方面的理论知识。

\section{2 实践技能培养模块}

解决工程实际问题的能力是表征应用 型人才能力高低的一个最重要标志。因此, 实践技能的培训必须贯穿于应用型人才培 养的整个教育过程。实践技能培养体系可分 为课程教学实践环节、独立实训实践环节和 实习基地建设三个部分。

\subsection{1 课程教学实践环节}

课程实践环节应与理论教学相结合, 以 加深对理论知识的理解与验证, 如力学实 验、物理课程实验、汽车油耗实验、汽车排 放测试实验等。

\subsection{2 独立实训实践环节}

独立实训实践环节以实训和模拟为主 要特征, 通过解决类似于工程实际问题, 培 养学生的动手技能和解决实践问题的能力。 主要包括三部分：一是金工实习、驾驶实习 等基本技能层, 进行工科基本技能训练。二 是机械制图测绘、机械设计基础课程设计、 电工电子实习等专业技能训练层, 进行理论 知识的综合运用和设计能力的训练。三是汽 车构造实习、发动机拆装实习、汽车故障检 测诊断实习等工程实践与创新能力层, 训练 解决工程实际问题的能力。

为了进一步加强训练解决工程实践问 题的能力, 在课程实践环节中增加了如汽车 $\mathrm{CAD} / \mathrm{CAE}$ 等课程的实践课时, 并对CATIA 设计软件的基础应用进行培训。在独立实训 实践环节中增设车辆工程综合实验、汽车电 控系统仿真与设计课程设计等内容, 以提高 学生今后的应用技能。

毕业设计 (论文) 是独立实训实践环节 的一项重要内容, 可提高学生对大学期间学 习成果的总结和运用能力。毕业设计可采用 “双导师制”, 由同捷公司的工程师和学校 专任教师共同担当指导教师。设计(论文)题 目可参考企业的实际项目选取, 如发动机舱
盖的逆向设计、汽车零部件的CAE仿真分析 等。

\subsection{3 产学研实习基地建设}

在车辆工程应用型人才培养模式探索 的过程中, 应逐步加强与汽车企业的合作交 流, 建立产学研实习基地, 充分发挥校企资 源优势, 积极研究工学结合、校企优势互补、 互利双赢的合作模式, 促进科研与教学紧密 结合。产学研实习基地的拓展与建设将为应 用型人才培养模式提供有力的保障, 能够锻 炼学生的工程实践能力, 全面提高学生的培 养质量, 推进应用型车辆工程专业人才培养 与企业接轨。

近年来, 汽车学院已与上海同捷科技股 份有限公司、众力汽车部件有限公司等企业 建立了长期稳定的毕业实习基地。通过在实 习基地的学习, 学生增加了感性认识, 毕业 后能够马上进入角色, 充分提高了学生的创 新意识和实践应用能力。

\section{3 综合素质培养体系}

构建素质拓展教育平台, 通过马克思主 义与爱国主义教育、外语、心里健康和人文 社会科学等育人课程的学习, 使学生建立科 学的世界观、人生观, 培养学生的团队合作, 社会交际能力。

为了进一步提高应用型人才的适应性 和知识面的宽广性, 在车辆工程专业课程平 台中增设了丰富的选修课程, 如汽车 $\mathrm{ECU}$ 应用、汽车安全技术、电子线路 CAD、汽 车营销学等课程。

为提高应用技能, 更好地对接企业, 企 业可开设汽车设计规范、流程标准和企业文 化等课程, 进一步加强学生对理论知识的实 际运用与操作能力。

\section{4. 结束语}

应用型车辆工程专业人才培养是一个 系统工程, 只有不断探索和完善车辆工程专 业的人才培养方案, 才能培养出满足社会市 场需求且具有创新和实践能力的高素质应 用型人才。在人才培养过程中, 应加强与企 业的沟通和交流，掌握企业的新技术、新方 
法、新需求, 从而对人才培养的方向和内容 不断加以充实和更新。

本文在对上海同捷等汽车企业需求调 研的基础上, 逐步完善人才培养方案, 积极 探索应用型人才的培养模式, 为车辆工程专 业人才的培养提供借鉴与参考。

\section{致谢}

本文为上海电机学院重点教研教改项 目(A1-5401-15-001 -05-10)和上海市自然科 学基金项目(13ZR1417400)的阶段性成果之

\section{References}

[1] K. C. Yi, H. Y. Chen, F. L. Dong, Reconstruction of training program for vehicle engineering practical talents[J], Course Education Research, vol.8, pp. 24-25, 2012.

[2] J. Fu, J. W. He, T. Tang, Research on curriculum system reform to improve vehicle engineering talents innovation ability[J], Science and Technology Innovation Herald, vol. 10, pp.1-2, 2013.

[3] Z. J. Long, K. Zi, T. Zhu, Research on practical talents cultivation plan of automotive engineering $[\mathrm{J}]$, China Modern Education Equipment, vol. 11, pp. 134-136, 2010.

[4] Y. Han, Z. X. Lu, H. Li, etc, Research and exploration of vehicle engineering discipline excellent engineer cultivation [J], Education Teaching Forum, vol. 8, pp. 263-265, 2015.

[5] H. Gao, J. L. Hu, J. L. Liu, etc, Research on practical applied talent cultivation mode of vehicle engineering [J]. Theory Research, vol. 24, pp. 260-262, 2010.

[6] M. Duan, T. L. Wang, Y. G. Tian, Resaech and practice on cooperative training mode of vehicle engineering [J]. Journal of Liaoning Institute of Technology, vol. 9, pp.106-108, 2007. 